\title{
Conserving and utilizing intra-varietal variation in grapevines (Vitis vinifera L.)
}

\author{
Ernst Ruehl, Hubert Konrad, and Bettina Lindner \\ Hochschule Geisenheim, Institute for Grapevine Breeding, von Lade Str. 1, 65366 Geisenheim, Germany
}

\begin{abstract}
Climate change poses a major challenge to grapevine growing and breeding. Higher temperatures and altered rain patterns will result in a shift of varieties to other areas or require the adaptation of varieties in their traditional growing regions. A large intra-varietal variation is a prerequisite for this task. Clonal selection is an important part of genetic improvement in grapevines. In contrast to cross breeding, it depends on the already existing genetic diversity within a variety. Due to their age, genetic diversity in traditional varieties can be quite large, providing the basis for new clones, better suited to altered climatic conditions and industry demands. In Germany clonal selection commenced already at the end of the 19th century, presumably due to the fact that under its cool climatic conditions virus infection, in particular fanleaf reduces crop dramatically. These first attempts were so successful that they were copied by numerous private and public breeders, and since the mid-1950s virtually only clonal material is being planted.
\end{abstract}

\section{Introduction}

Grapevines are usually propagated by vegetative propagation, which preserves a genotype and allows an easy mass-propagation. This is certainly a major reason for the early domestication of grapevines. Due to their old age most grapevine varieties - compared to other crops have developed a certain intra-varietal genetic variability. Triggered by mutations and preserved by vegetative propagation, variation can be quite large and in case of distinct characteristics may even lead to new varieties. This e.g. is the case with Pinot varieties, where we see Pinot Noir with blue berries, Pinot Gris with red and Pinot Blanc with white ones. Apart from these extreme examples, most mutations have only small effects and stay well within the range of the variety. Examples are differences in yield, acidity, direction of shoot growth, development of lateral shoots, berry size, peduncle or pedicel length. This variation provides the source for clonal selection and permits the development of clones with new characteristics.

Selection and propagation of superior vines is most likely as old as viticulture and provided the basis for its success. First written reports date back to Roman times, summarized by Columella [1]. Modern clonal selection in Germany commenced in the $19^{\text {th }}$ century with the work of Gustav Froelich [1] and proved so successful that from mid-1950s most vineyards were established with clonal propagation material. As a consequence the acreage of vineyards planted with non-clonal material diminished significantly and is today less than 500 ha [2]. The decline of these vineyards poses the threat of losing valuable genetic material.

Collecting, preserving and assessing potentially different genotypes of traditional varieties are an ongoing process in clonal selection. At the Geisenheim breeding

${ }^{a}$ Corresponding author: rudolf.ries@hs-gm.de institute this task was intensified first during the 1980s, predominantly for Pinot Noir and again in the middle of the 1990s mostly for White Riesling and other Pinot varieties. Until today more than 1000 accessions of White Riesling and more than 500 of Pinot varieties have been preserved in the institute's breeding fields. Despite the fact that this task of collecting diverse genetic material is not focused on specific characteristics, the assessment of these accessions occasionally yields clonal candidates with characteristics demanded by growers.

Major current and future challenges to grape breeding are the growing effects of global warming. While 50 years ago, under cooler conditions, traditional German varieties were ripening as late as October or even November, in recent years ripening commenced already in September or even August under significantly warmer and much more favorable conditions for bunch rot. The aim of this study was to assess genetic diversity within traditional German varieties and to identify clones better suited to the challenges of climate change, predominantly in regards to botrytis infection and low acidity.

\section{Material and methods}

Vines assessed in this study resulted from the institute's clonal collection, were tested negative for GLRaV-1 and GLRaV-3, ArMV and GFLV and were planted in plots of at least 12 vines each in the Institute's breeding fields at Geisenheim, Germany. Soil is a fertile deep sandy loam derived from loess. Training system was a VSP, row spacing $1.8 \mathrm{~m}$; the trellis consisted of two fruiting wires at 80 and $100 \mathrm{~cm}$ and two pairs of movable foliage wires. Every second row was cultivated at least once each year; the other row planted with a grass herb mixture and slashed regularly.

In case of the Riesling trial, clones 198-44 Gm and 239-34 Gm were used as comparison. For Chardonnay, 
according to their bunch structure, clones are grouped as type B: small, rather tight bunches, small berries, lower yield and lower acidity and type $C$ : larger less tight bunches, larger berries, higher yield and higher acidity. Chardonnay clone $52 \mathrm{Gm}$ is an example of type B and used as a direct comparison for Chardonnay Roseclone $1 \mathrm{Gm}$, a red mutant of Chardonnay. The two Pinot Gris clones, 1-33 Gm and $27 \mathrm{Gm}$ are both clones with open bunch architecture. In case of clone $1-33 \mathrm{Gm}$ this is caused by longer pedicels and in case of clone $27 \mathrm{Gm}$ by smaller berries.

Grapes were harvested when fully ripe, botrytis infection, yield, titratable acidity and sugar concentration recorded. Data are means of harvests of - depending on the variety - 2007-2014 or 2008-2014. Means and standard deviations were calculated with Excel, factor analysis was conducted from Riesling clone means with SYSTAT and factor rotation with the VARIMAX model.

\section{Results and discussion}

The performance of White Riesling clones in the trial varied significantly (Fig. 1). Highest yields were observed in one of the standard clones $(239-34 \mathrm{Gm})$ with $1654 \mathrm{~g} / \mathrm{m}^{2}$. Some of the new clones also had yields between 1550 and $1600 \mathrm{~g} / \mathrm{m}^{2}$. In contrast to that clone $355 \mathrm{Gm}$ had lowest average yield with less than $800 \mathrm{~g} / \mathrm{m}^{2}$.

Variation of total soluble solids between clones was less than 2 Brix, with a rather high standard deviation due to seasonal differences. Variation in titratable acidity was

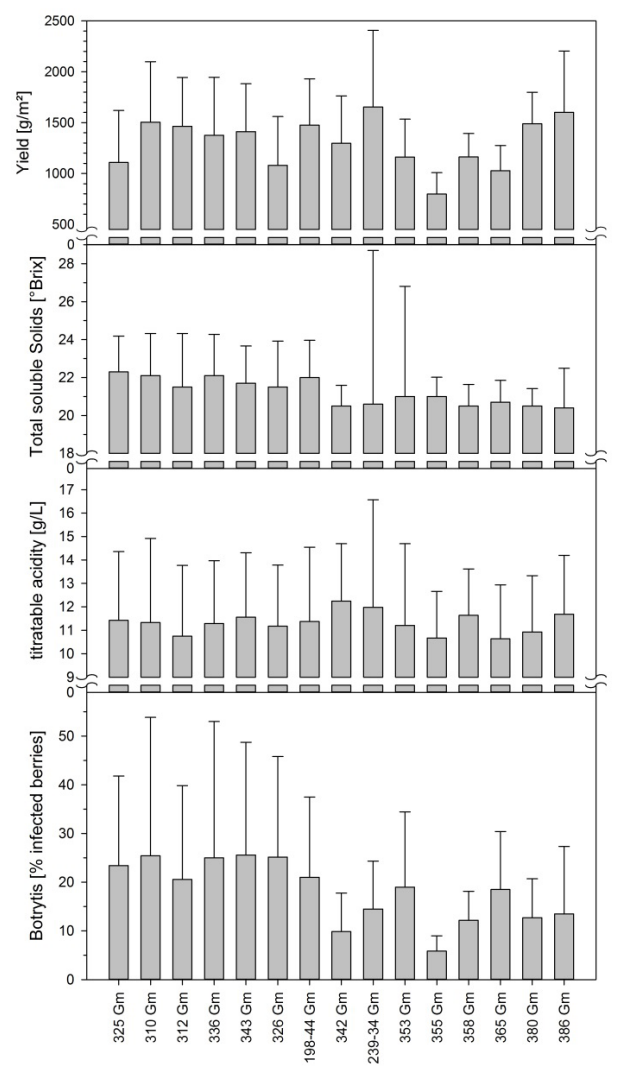

Figure 1. Performance of Riesling clones. Results are mean of 2008-2014. also considerably small with a strong variation between seasons too.

Botrytis infection was strongly dependent on clones. While some clones had on average more than $25 \%$ infected berries, clone $342 \mathrm{Gm}$ had only $10 \%$ and clone $355 \mathrm{Gm}$ only $6 \%$ infected berries.

Results indicate that clones with different yield levels can be developed rather easily, due to the large diversity in the clonal population. The same applies to tolerance to botrytis. Clones $342 \mathrm{Gm}$ and $355 \mathrm{Gm}$ are less susceptible than most other clones. Clone $355 \mathrm{Gm}$ is also low yielding, due to considerably small bunches, but clone $342 \mathrm{Gm}$ has a rather average yield of $1300 \mathrm{~g} / \mathrm{m}^{2}$, which indicates that low susceptibility to botrytis is not linked to yield. Results

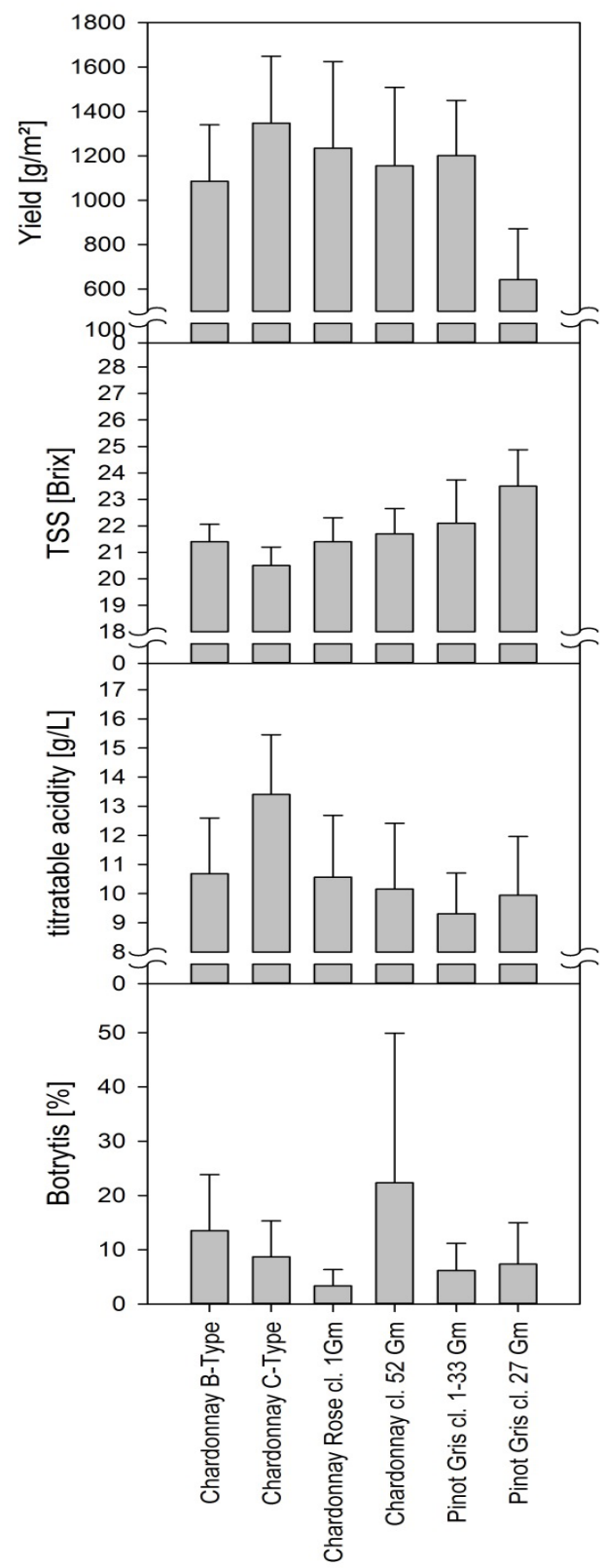

Figure 2. Performance of Chardonnay and Pinot Gris clones. Results are mean of 2008-2014. 

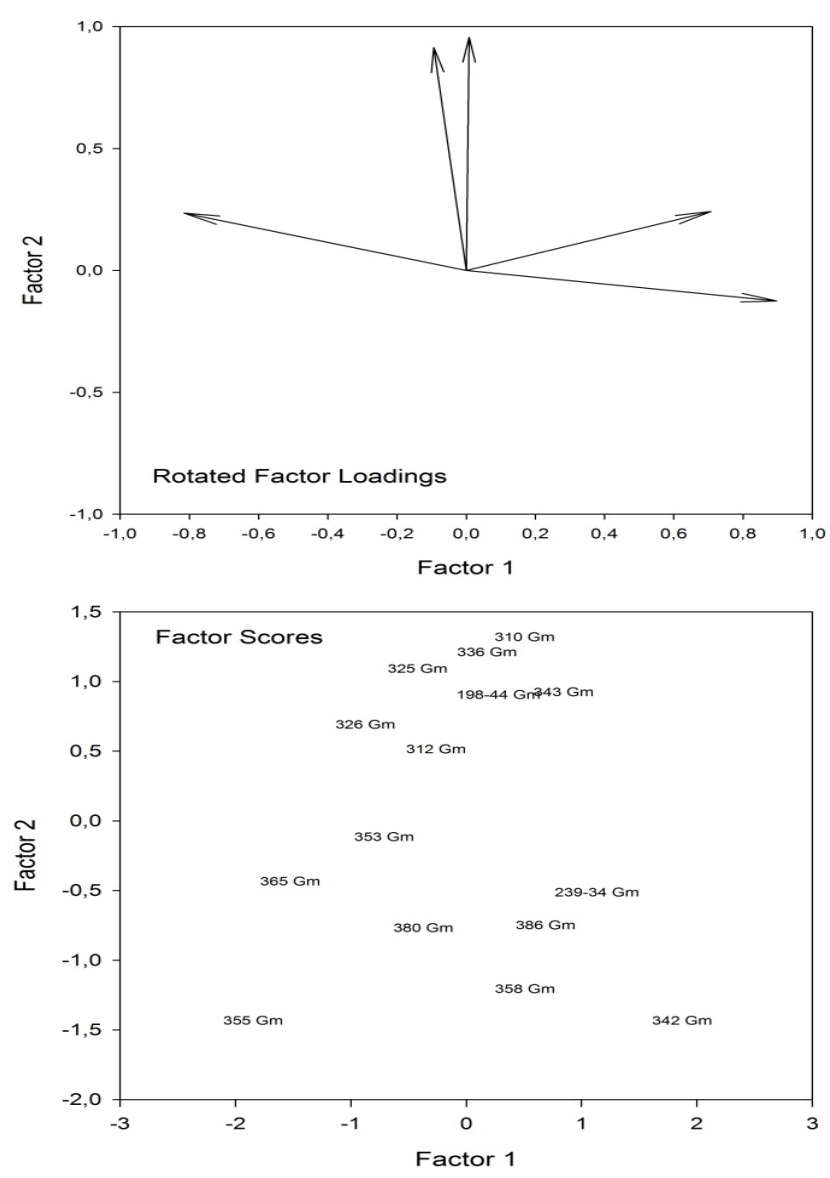

Figure 3. Factor loadings and Factor scores of White Riesling clones after factor rotation with Varimax.

are in agreement with observations on Riesling and Pinot clones studied earlier [3].

Results on Chardonnay and Pinot Gris clones also indicate performance differences (Fig. 2). Chardonnay clones of type $\mathrm{C}$ showed highest yield, highest titratable acidity and lowest sugar level, compared to Chardonnay type B clones. Bunches also look different. While those of type $\mathrm{C}$ clones are rather large and with a loose architecture those of type B clones are smaller, tighter, resulting in less yield, higher sugar levels, less acidity, but higher susceptibility to botrytis. An interesting result is the low botrytis incident of Chardonnay Rose, as a comparison Chardonnay clone $52 \mathrm{Gm}$, growing next to it, showed significantly higher botrytis susceptibility of more than $20 \%$ infected berries on average. Sugar and acidity levels of this Chardonnay mutant are similar to that of type B clones, but the yield is higher and the botrytis susceptibility with only $3 \%$ rather low. As wine style is similar to white Chardonnay clones, Chardonnay Rose might provide an alternative to these clones in case of high botrytis pressure at humid sites.

Both Pinot Gris clones show that low incidents of botrytis are achievable either with longer pedicels (clone
1-33 Gm) or with smaller berries (clone $27 \mathrm{Gm}$ ). As a consequence of these smaller berries, yield of this clone is significantly lower.

A frequent problem in clonal trials is to analyze and show the performance of a large number of clones. Most clonal comparisons focus on yield and total soluble solids and plot them in a scatter graph, as these are generally considered the two most important characters. This leaves other parameters out of consideration. Therefore, with the means of Riesling clones, a factorial analysis was conducted. After rotation two factors could explain variation in the performance data of Riesling with Eigen values factor $1=2.147$ and factor $2=1.713$. No other factor had a significant influence. Factor 1 has highest loadings for titratable acidity $(0.897), \mathrm{pH}(-0.816)$ and yield $(0.707)$ (Fig. 3). Factor 2 had highest loadings for percentage of botrytis infected berries (0.956) and total soluble solids (Brix) (0.914). Clones with a high yield generally had high titratable acidity and a low $\mathrm{pH}$, which is most likely linked to a delay in ripening of high yielding clones. This is shown in factor 1. Factor 2 indicates a correlation between botrytis infection and total soluble solids (Brix). Larger numbers of botrytis infected berries presumably increased sugar concentration in infected berries by a higher water loss, similar to the processes of "noble rot".

Accordingly, clones can be characterized by their factor scores. Clones in the lower part of the graph have low botrytis incident, those in the right part of the graph show a high yield, while those in the left part a low one. E.g. clone $355 \mathrm{Gm}$ has both low yield and low botrytis susceptibility.

\section{Conclusions}

Variability within traditional cultivars - in this case Riesling, Chardonnay and Pinot Gris - can be quite large. This is not only the case in characters like yield, but also in titratable acidity and botrytis infection. Particularly those two parameters are of major importance to develop clones with less susceptibility to botrytis and with higher acidity, which are important to cope with the effects of climate change in Central Europe.

The use of factorial analysis might provide a useful tool to assess and characterize the performance of clones.

\section{References}

[1] Schöffling, H., Stellmach, G.. 1993. Klon-Züchtung bei Weinreben in Deutschland. Waldkircher Verlag.

[2] Weihl, T. 2010 Personal communication.

[3] Rühl, E.; Konrad, H.; Schönhals, E. M. (2009): Untersuchung zur Existenz und zum Ausmaß genetischer Variation traditioneller Rebsorten im Hinblick auf die Erhaltung genetischer Ressourcen. Erfassung der physiologischen Kennzahlen der Klone. Bundesanstalt für Landwirtschaft und Ernährung. Bonn (Forschungsprojekt, 514-33.52/04HS021). http: / / download.ble.de/04HS021.pdf . 